\title{
COMPORTAMIENTO DE VARIEDADES DE MAÍZ NORMAL Y CON ALTA CALIDAD DE PROTEÍNA PARA LA REGIÓN GOLFO DE MÉXICO1
}

\author{
Mauro Sierra ${ }^{2}$, Artemio Palafox ${ }^{2}$, Octavio Cano ${ }^{2}$, Sergio Uribe ${ }^{2}$, Enrique Noé Becerra ${ }^{2}$, David Lara ${ }^{3}$, Sabel \\ Barrón ${ }^{4}$, Flavio Rodríguez ${ }^{2}$, José Romero ${ }^{5}$, Alfredo Sandoval ${ }^{6}$
}

\begin{abstract}
RESUMEN
Comportamiento de variedades de maíz normal y con alta calidad de proteína para la región Golfo de México. Durante el ciclo Primavera - Verano 2001, se estableció un ensayo uniforme de variedades de maíz normal y con alta calidad de proteína en cuatro localidades del estado de Veracruz (Cotaxtla, Papantla, Isla, y San Andrés Tuxtla), y Huimanguillo en el estado de Tabasco. Se evaluó el rendimiento y características agronómicas para definir su adaptabilidad bajo condiciones de temporal. El diseño usado fue alpha látice 4 × 8 con 32 tratamientos y dos repeticiones, en parcelas de dos surcos de $5 \mathrm{~m}$ de largo separados a $80 \mathrm{~cm}$. Del análisis combinado para rendimiento de grano, se encontró diferencia altamente significativa para variedades $(\mathrm{V})$, localidades (L) y para la interacción Vx L. Los genotipos sobresalientes fueron los sintéticos normales SINT 3 SEQ, VS-536 y SINT 9 SEQ y las variedades con alta calidad de proteína SINT 1 Q, V-537C, y V-537C Comp. 1. Estos genotipos registraron buen aspecto y sanidad de planta y mazorca. Particularmente en las localidades Cotaxtla, Papantla y San Andrés Tuxtla, V-537C Comp. 1 que corresponde a un ciclo de selección recurrente de progenies S1 de V-537C, registró ventajas en rendimiento, aspecto y sanidad de planta y de mazorca, acame, cobertura y pudrición de mazorca, con relación al V-537C original.
\end{abstract}

\begin{abstract}
Behaviour of normal and high quality protein maize varieties for the Gulf of Mexico region. During Spring Summer season in 2001 experiments of normal and high quality protein maize were conducted in four locations in the Veracruz State (Cotaxtla, Papantla, Isla and San Andres Tuxtla) and Huimanguillo in Tabasco State, to evaluate their yield and agronomic characteristics and to define their adaptability under these environments. Thus, the experiments were stablished under alpha lattice designs 4 x 8 with 32 entries and two replications, in plots with two $5 \mathrm{~m}$ long rows and $80 \mathrm{~cm}$ between them. The combined analysis for grain yield showed highly significant differences for varieties (V), locations (L) and for the interaction Vx L. Among the best genotypes at 0.05 of probability are the normal synthetic varieties formed with drought tolerant inbred lines, SINT 3 SEQ, VS-536 y SINT 9 SEQ and the high quality protein maize varieties SINT 1 Q, V-537C, y V-537C Comp. 1. In reference to the agronomic characteristics, these genotypes registered good ear and plant aspect and healthiness. Particulary in Cotaxtla, Papantla and San Andres Tuxtla, V537C Comp 1 (which correspond to the first S1 families recurrent selection cycle of V-537C), registered important advantages in yield, ear and plant aspect, lodging, husk cover and ear rot.
\end{abstract}

\section{INTRODUCCIÓN}

El cultivo de maíz en México es el más importante debido a la superficie sembrada, valor de la producción, por ser el alimento principal de la población y por ocupar el 20\% de la población económicamente activa. Durante 1998, se sembraron a nivel nacional 7,9 millones de hectáreas con un rendimiento medio de 2,3 t/ha y una

\footnotetext{
1 Recibido para publicación el 21 de febrero del 2003. Presentado en la XLVIII Reunión anual del PCCMCA, República Dominicana, 2002.

2 Programa de maíz del Campo experimental Cotaxtla. Apdo postal 429, Veracruz, Ver. México CP 91700. mauro_s55@hotmail.com.

3 Tesista en el programa de maíz del Campo Cotactla. ITA No. 18 Ursulo Galván, Ver.

4 Campo Experimental Huimanguillo. Huimanguillo, Tab.

5 Campo Experimental Papaloapan. Isla, Ver.

6 Campo Experimental Ixtacuaco, Ixtacuaco, Ver.
} 
producción de 18,47 millones de toneladas (SAGAR 1998). Aún cuando el maíz tiene múltiples usos, el principal es el consumo directo y en diferentes formas en la alimentación humana (200 kg per cápita), y en menor proporción se utiliza en la alimentación de ganado. En el trópico húmedo de México se sembraron 2,75 millones de hectáreas y para los estados de Veracruz y Tabasco fueron sembradas 642.000 ha de las cuales 492.000 ha se sembraron durante el ciclo Primavera - Verano, y 150.000 ha en el ciclo otoño - invierno bajo condiciones de tonalmil, siembra que se logra con la humedad residual del temporal y las lluvias ocasionadas por los vientos "nortes", principalmente durante los meses de octubre a marzo. En este ciclo agrícola, durante los meses de marzo a mayo el maíz se ve afectado por falta de agua la cual coincide con el período de llenado de grano y merma significativamente el rendimiento Sierra (2000). Así también, las siembras establecidas durante el ciclo primavera - verano bajo temporal, sobretodo en climas Aw0 y Aw1, García (1981) se ven afectados por la sequía intraestival conocida como "canícula", la cual ocurre durante los meses de julio y agosto y coincide con el período de floración e inicial de llenado de grano, que son las etapas fenológicas cuando más se afecta el maíz y provoca pérdidas significativas en el rendimiento. De acuerdo con Edmeades et al. (1996), y Edmeades et al. (1999), mencionan que después de la fertilidad, la sequía es el principal stress abiótico que limita la producción de maíz en los trópicos

Una forma de lograr incrementos significativos y minimizar los riesgos en la producción es mediante el uso de semillas mejoradas, las que son más eficientes en el aprovechamiento de los recursos naturales disponibles. Particularmente, las variedades sintéticas se adaptan más fácilmente a las diferentas condiciones de clima, suelo y manejo por parte de los agricultores; tienen la ventaja de que pueden ser usados por varios ciclos de siembra sin que decaiga el rendimiento y es más fácil la producción de semilla

La formación de variedades de maíz con alta calidad de proteína es una actividad con alto contenido social encaminado a fortalecer el nivel nutricional, sobretodo en la población infantil de las áreas rurales. El maíz con alta calidad de proteína es un derivado del gene mutante $\mathrm{o} 2 \mathrm{o} 2$, que se expresa en su versión homocigótica recesiva con mayor contenido de Lisina y Triptofano, aminoácidos esenciales en la alimentación, este hecho fue descubierto por Mertz et al (1964) y reportado por Mertz (1994). Durante las décadas de los 60s y 70s los programas nacionales de muchos países en vías de desarrollo realizaron esfuerzos para convertir sus materiales genéticos a este carácter, tan claramente deseable. Particularmente el programa de maíz del INIA, antecesor del actual INIFAP en México, convirtió sus principales híbridos y variedades de polinización libre, tal es el caso en el trópico del H-507 en su versión opaco. Gerón et al (1979). Sin embargo, al alto valor nutritivo de estos maíces iban ligadas varias características indeseables como son: grano de textura almidonosa y de bajo peso, poca resistencia a plagas del almacén y a pudriciones, principalmente por hongos.

Vasal et al. (1994), siguieron el camino de concentrar genes modificadores del endospermo para lograr la textura cristalina o dentada sobre el grano que expresa el gene o2o2. Larkins et al (1994) mencionan que los maíces con el gene 0202 son $40-50 \%$ más ricos en Lisina y 35-40\% más ricos en Triptofano en relación con el maíz normal. La herencia del carácter " grano modificado", sugieren que se trata de dos genes codominantes no ligados. Estos genes incrementan la síntesis del grupo gama zeína y con esto propician cierta formación de cuerpos proteicos que a su vez podrían ser los factores de la textura cristalina del endospermo. Con relación a la evaluación de genotipos, Sierra et al. (1999) reportaron que durante los ciclos primavera - verano 1997/97 y 1998/98 y otoño - invierno 1998/99, dentro del convenio de colaboración INIFAP-CIMMYT se condujeron en el sureste de México, experimentos de híbridos y variedades de maíz de alta calidad proteica de los que resultaron sobresalientes las cruzas CML $172 \mathrm{X}$ P66HC22-2-5-2-BB de grano amarillo, (CML142XCML150)XCML176, (CLQ62XCML150) XCML176, CML 144 X CML 159 y CML 142 X CML 146 y la variedad de polinización libre PR8763TLW de grano blanco, los que registraron rendimientos equiparables con los testigos normales CML 247 X CML 254 y H-516.

Con relación a la interacción genotipo ambiente, Márquez (1992), Márquez (1988), Carballo y Márquez (1970) y Sierra et al. (1992) han usado los parámetros de estabilidad propuestos por Eberhart y Russell (1966) para seleccionar genotipos en función de su respuesta a través de diferentes ambientes; Particularmente, Carballo y Márquez (1970) definieron seis situaciones posibles en función del significado de los valores del coeficiente de regresión (Bi) y de las desviaciones de regresión $\mathrm{S}^{2}$ di. Así definieron una variedad estable aquella con valores de $\mathrm{Bi}=1$ y S $\mathrm{S}^{2} \mathrm{di}=0$; Así también, los genotipos con alto rendimiento y estables fueron descritos como "deseables".

El identificar genotipos con alto rendimiento y adaptación al trópico Mexicano pero con mayor calidad de proteína (Lisina y Triptofano) el cual es un valor agregado con alto contenido social que puede ayudar a disminuir la desnutrición en México. 


\section{Objetivos}

- Conocer el rendimiento y las características agronómicas de variedades de maíz formadas con líneas tolerantes a sequía y variedades con alta calidad de proteína en los estados de Veracruz y Tabasco.

- Definir la adaptabilidad de los genotipos bajo condiciones de temporal a través de los ambientes de evaluación.

\section{MATERIALES Y MÉTODOS}

Durante el ciclo primavera - verano 2001, se estableció en la región Golfo de México un ensayo uniforme de variedades de maíz normal y con alta calidad de proteína en las localidades de Cotaxtla, Papantla, Isla y San Andrés Tuxtla, Ver y Huimanguillo, Tab que de acuerdo con la clasificación climática de Köppen modificada por García (1981) corresponde al grupo climático A que engloba a los climas cálido húmedo y subhúmedo y de los cuales se describen sus características en el Cuadro 1.

Germoplasma utilizado. El germoplasma utilizado en la presente investigación fueron 17 variedades experimentales de maíz con alta calidad de proteína, 13 sintéticos de maíz seleccionados para tolerancia a sequía y los testigos comerciales normales VS-536 y V-530.

Descripción de los experimentos. Durante el ciclo primavera - verano 2001 se estableció un ensayo uniforme para evaluar variedades de maíz normal y con alta calidad de proteína en cinco ambientes en los estados de Veracruz y Tabasco. El diseño usado para la siembra fue Alpha látice 4 x 8 con 32 tratamientos y dos repeticiones en parcelas de dos surcos de $5 \mathrm{~m}$ de largo separados a $80 \mathrm{~cm}$ depositando a la siembra dos semillas cada $20 \mathrm{~cm}$ para dejar una planta después de la segunda labor, es decir, una densidad de población de 62.500 plantas por hectárea. La fertilización se hizo con la fórmula 161-46-00 para la localidad de Cotaxtla, 138-69-00 en Ejido Oro Verde, Mio. de Isla, Ver. y 120 40-30 para Huimanguillo, Tab.

Variables y registro de datos. Durante el desarrollo del cultivo fueron registradas las siguientes variables: altura de planta y mazorca, días a flor masculina y femenina, aspecto de planta y mazorca, sanidad de planta y mazorca , \% de plantas acamadas, $\%$ mazorcas con mala cobertura \% de mazorcas podridas (Fusarium y Diplodia), \% de materia seca, $\%$ de grano y rendimiento de grano ajustado al $12 \%$ de humedad..

Métodos estadísticos. Se hicieron análisis de varianza individuales de las variables para cada experimento, y un análisis combinado para rendimiento de grano a través de los cinco ambientes de evaluación, de los cuales se obtuvo la significancia y el valor de la DMS al 0,05 y 0,01 de probabilidad (Reyes 1990 y Reyes 1985). Así también se caracterizaron los sintéticos en función de su respuesta a los ambientes a través del método de parámetros de estabilidad descritos por Eberhart y Russell (1966). Las variables registradas en porcentaje fueron transformadas a grados angulares para su análisis.

\section{RESULTADOS Y DISCUSIÓN}

El Cuadro 2 registra los cuadrados medios, significancia, valores medios y coeficientes de variación de

Cuadro 1. Localidades de evaluación de variedades de maíz con alta calidad de proteína. CIRGOC. 2001B.

\begin{tabular}{lcclcccccc}
\hline Localidad & Clima & $\begin{array}{c}\text { Asnm } \\
\text { M }\end{array}$ & $\begin{array}{c}\text { Tipo de } \\
\text { Suelo }\end{array}$ & $\begin{array}{c}\text { Ph } \\
\text { Mm }\end{array}$ & Temp & Pend & Mo & Dren & Prec \\
\hline Cotaxtla & Aw1 & 15 & Franco & 7,0 & 25 & $<1 \%$ & $>3 \%$ & Bueno & 1300 \\
Papantla & Aw2 & 298 & Arcillo & 7,0 & 24 & $<1 \%$ & $>1 \%$ & Lento & 1170 \\
& & & Limoso & & & & & & \\
Isla & Aw1 & 80 & Fluvisol eutrico & 6,0 & 24 & $<1 \%$ & $1 \%$ & Bueno & 1100 \\
$\begin{array}{l}\text { San andres } \\
\text { tuxtla }\end{array}$ & Am & 360 & Arcilloso & 6,5 & 24,5 & $<5 \%$ & $>3 \%$ & Lento & 1996 \\
$\begin{array}{l}\text { Huiman } \\
\text { Guillo }\end{array}$ & Am & 25 & Franco arcillo & 7,0 & 26,2 & $<1 \%$ & $>3 \%$ & Lento & 2290 \\
\hline
\end{tabular}


Cuadro 2. Cuadrados medios, significancia para tratamientos, coeficientes de variación y valores medios para variedades de maíz con alta calidad de proteína. CIRGOC 2001B.

\begin{tabular}{|c|c|c|c|c|c|c|c|c|c|}
\hline Loc & $\begin{array}{c}\text { Rend } \\
\text { t/ha }\end{array}$ & $\begin{array}{c}\text { Asp } \\
\text { PI }\end{array}$ & $\begin{array}{l}\text { Asp } \\
\text { Mz }\end{array}$ & $\begin{array}{c}\text { San } \\
\text { PI }\end{array}$ & $\begin{array}{l}\text { San } \\
\text { Mz }\end{array}$ & $\begin{array}{c}\% \\
\text { Pod }\end{array}$ & $\begin{array}{c}\text { Alt } \\
\text { PI }\end{array}$ & $\begin{array}{c}\text { Alt } \\
\text { mz }\end{array}$ & $\begin{array}{l}\text { Días } \\
\text { Flor }\end{array}$ \\
\hline Cot $\mathrm{cm}$ & $1,38 *$ & $0,19 \mathrm{~ns}$ & $0,40 \mathrm{~ns}$ & $0,76 \mathrm{~ns}$ & $0,48^{*}$ & 1,16 & $232,8 \mathrm{~ns}$ & $205,8 \mathrm{~ns}$ & $1,98 \mathrm{~ns}$ \\
\hline $\mathrm{Cv}$ & 10,1 & 14,0 & 19,3 & 7,0 & 15,7 & 35,7 & 4,5 & 7,6 & 2,8 \\
\hline Prom & 7,10 & 2,91 & 2,67 & 2,81 & 2,89 & 9,42 & 254,8 & 133,7 & 51,34 \\
\hline Pap cm & $1,38 \mathrm{~ns}$ & 0,25 & 1,24 & 0,25 & & $0,87 \mathrm{~ns}$ & $158,6 \mathrm{~ns}$ & $106,78 \mathrm{~ns}$ & $0,98 \mathrm{~ns}$ \\
\hline $\mathrm{Cv}$ & 14,7 & 8,9 & 19,1 & 8,9 & ------ & 40,4 & 5,8 & 8,5 & 1,8 \\
\hline Prom & 6,00 & 5,28 & 5,16 & 5,28 & & 6,05 & 207,5 & 104,70 & 48,53 \\
\hline Isla $\mathrm{cm}$ & $0,537 *$ & $0,37 *$ & $0,29 \mathrm{~ns}$ & $0,23 *$ & $0,39 *$ & & & & \\
\hline $\mathrm{Cv}$ & 15,11 & 14,44 & 14,50 & 11,95 & 15,55 & ----- & ----- & ----- & ----- \\
\hline Prom & 3,84 & 3,08 & 3,06 & 2,84 & 2,97 & & & & \\
\hline Sat $\mathrm{cm}$ & $0,84 *$ & $0,39 \mathrm{~ns}$ & $0,33 \mathrm{~ns}$ & $0,35 \mathrm{~ns}$ & $0,42 \mathrm{~ns}$ & $1,76 \mathrm{~ns}$ & & & \\
\hline $\mathrm{Cv}$ & 17,49 & 14,32 & 19,97 & 16,0 & 20,2 & 32,29 & ----- & ----- & ----- \\
\hline Prom & 3,97 & 2,7 & 2,51 & 2,87 & 2,65 & 3,62 & & & \\
\hline Huim $\mathrm{cm}$ & $1,75^{*}$ & $0,44 \mathrm{~ns}$ & $0,39 \mathrm{~ns}$ & & $0,49 \mathrm{~ns}$ & $0,63 \mathrm{~ns}$ & $318,8^{*}$ & $241,87 * *$ & $2,76^{*}$ \\
\hline $\mathrm{Cv}$ & 16,8 & 6,5 & 7,1 & ----- & 7,6 & 39,9 & 4,6 & 6,6 & 2,1 \\
\hline Prom & 5,08 & 7,25 & 8,29 & & 7,88 & 2,28 & 248,1 & 118,13 & 51,09 \\
\hline
\end{tabular}

Cot $=$ Cotaxtla, Pap $=$ Papantla, Sat $=$ San Andres Tuxtla y Huim=Huimanguillo.

* = Significancia de la comparación al 0,05 de probabilidad

** = Significancia de la comparación al 0,01 de probabilidad

las variables para cada localidad. Se encontró de acuerdo con Reyes (1985), significancia estadística para la mayoría de las variables analizadas. Así, para la localidad de Cotaxtla que se encontró significancia para tratamientos en las variables: rendimiento de grano, sanidad de mazorca y porciento de acame. Para la localidad de Papantla, no hubo diferencia significativa entre tratamientos. En Isla Ver. se registró diferencia significativa en las variables: Rendimiento, aspecto de planta, sanidad de planta. En San Andrés Tuxtla sólo se registró diferencia significativa para tratamientos en la variable rendimiento de grano. Finalmente, para la localidad de Huimanguillo, Tab. se registró diferencia para tratamientos en las variables: Rendimiento de grano, altura de planta y mazorca, \% de acame y días a floración masculina y femenina. Por lo que se refiere a los coeficientes de variación estos en general fueron bajos, particularmente, para la variable rendimiento se registraron valores menores a $18 \%$, valores que sugieren que la conducción de los experimentos y los resultados obtenidos son confiables. Las variables que registraron los coeficientes de variación más altos fueron aquellas registradas en porcentaje tales como: \% de mazorcas podridas, $\%$ de daño por Diplodia, y \% de mazorcas con mala cobertura.

En el análisis de varianza combinado para la variable rendimiento de grano en los cinco ambientes de evaluación (Cuadro 3), se encontró diferencia altamen- te significativa para la fuentes de variación: variedades (V), ambientes (A), y para la interacción VXA, lo que significa que las variedades sintéticas responden de manera diferente a los ambientes de evaluación. Reyes (1990). Lo anterior sugiere efectos de interacción genotipo - ambiente (Márquez (1992), Márquez (1980), Márquez (1988), Márquez y Carballo (1970) y Sierra et al. (1992)). El valor del coeficiente de variación $(14,07 \%)$, es bajo, lo que sugiere de acuerdo con Reyes (1990), que la conducción de los experimentos y los resultados obtenidos son confiables.

Cuadro 3. Análisis de varianza combinado para rendimiento de grano de variedades de maíz con alta calidad de proteína. CIRGOC 2001B.

\begin{tabular}{lrrrrr}
\hline $\begin{array}{c}\text { Fuente } \\
\text { Variación }\end{array}$ & $\begin{array}{c}\text { Grados } \\
\text { libertad }\end{array}$ & $\begin{array}{c}\text { Suma } \\
\text { cuadrados }\end{array}$ & $\begin{array}{c}\text { Cuadrados } \\
\text { medios }\end{array}$ & F calc & prob \\
\hline Ambiente & 4 & 487,78 & 121.945 & $44,22^{* *}$ & 0,000 \\
RepX amb. & 5 & 13,79 & 2.758 & & \\
Variedades & 31 & 95,63 & 3.085 & $5,76^{* *}$ & 0,000 \\
Var X amb. & 124 & 107,28 & 0.865 & $1,61 * *$ & 0,002 \\
Error & 155 & 83,04 & 0.536 & & \\
\hline
\end{tabular}

$\mathrm{CV}=14,07 \%$

$* *$ = Significancia para las fuentes de variación al 0,01 de probabilidad 
Del análisis combinado y los parámetros de estabilidad propuestos por Eberhart y Russell (1966), realizados para rendimiento de grano para los cinco ambientes de evaluación, el Cuadro 4 muestra el rendimiento medio por localidad, a través de localidades y la descripción de acuerdo con los parámetros de estabilidad. Se encontró un grupo de 14 genotipos sobresalientes al 0,01 de probabilidad y descritos como "estables", es decir interaccionan poco con el ambiente, lo que los define de acuerdo con Carballo y Márquez (1970) como variedades "deseables". Entre ellos 10 sintéticos de sequía, el testigo VS-536, y las variedades con alta calidad de proteína SINT 1 Q, V-537C y V-537C comp. 1.
Por lo que se refiere a los rendimientos medios y los respectivos índices ambientales registrados en el análisis de parámetros de estabilidad para cada localidad (Cuadro 5), descritos por Eberhart y Russell (1966), se encontró que la localidad de Cotaxtla, registró el rendimiento medio más alto $(7,01 \mathrm{t} / \mathrm{ha})$, significativamente superior al 0,01 de probabilidad con un índice ambiental de 1,90. Por el contrario, las localidades de Isla y San Andrés Tuxtla, Ver. registraron rendimientos medios de 3,85 y 3,97 t/ha con índices ambientales de $-1,36$ y $-1,23$ para cada localidad, respectivamente.

La Figura 1 muestra las tendencias de respuesta de genotipos sobresalientes a través de los cinco ambientes

Cuadro 4. Rendimiento medio y parámetros de estabilidad de variedades de maíz con alta calidad de proteína. CIRGOC 2001B.

\begin{tabular}{|c|c|c|c|c|c|c|c|c|}
\hline \multirow[b]{2}{*}{ Trat. } & \multirow[b]{2}{*}{ Genealogía } & \multicolumn{7}{|c|}{ Rendimiento de grano en $\mathrm{t} / \mathrm{ha}$} \\
\hline & & Cot & Sat & Huim & Isla & Papan & Prom & Descripción \\
\hline 26 & SINT 3 SEQ & 8,32 & 4,45 & 6,61 & 4,7 & 6,98 & $6,21 *$ & ESTABLE \\
\hline 9 & VS-536 & 7,74 & 4,78 & 6,59 & 3,97 & 7,75 & $6,17 *$ & ESTABLE \\
\hline 30 & SINT 9 SEQ & 8,71 & 4,88 & 6,18 & 4,64 & 6,09 & $6,1 *$ & ESTABLE \\
\hline 27 & SINT 4 SEQ & 8,86 & 4,14 & 6,36 & 4,6 & 5,67 & $5,93^{*}$ & ESTABLE \\
\hline 20 & SINT 6 SEQ & 8,39 & 4,88 & 5,94 & 3,89 & 5,88 & $5,8^{*}$ & ESTABLE \\
\hline 28 & SINT 7 SEQ & 7,49 & 4,84 & 5,65 & 3,8 & 7,17 & $5,79 *$ & ESTABLE \\
\hline 31 & SINT 12 SEQ & 7,18 & 4,38 & 5,78 & 4,19 & 7,17 & $5,74 *$ & ESTABLE \\
\hline 22 & SINT LPS & 8,61 & 4,22 & 6,32 & 3,45 & 6,02 & $5,72 *$ & ESTABLE \\
\hline 5 & SINT $1 \mathrm{Q}$ & 7,52 & 4,78 & 5,39 & 4,57 & 6,28 & $5,71 *$ & ESTABLE \\
\hline 25 & SINT 1 SEQ & 7,35 & 4,81 & 5,4 & 4,09 & 6,11 & $5,55 * *$ & ESTABLE \\
\hline 7 & V-537 C & 7,7 & 3,7 & 5,43 & 4,45 & 6,01 & $5,46^{* *} *$ & ESTABLE \\
\hline 8 & V-537 C COMP,1 & 7,71 & 4,89 & 4,29 & 3,94 & 6,32 & $5,43 * *$ & ESTABLE \\
\hline 32 & SINT 13 SEQ & 7,31 & 2,97 & 5,4 & 4,9 & 6,55 & $5,43 * *$ & ESTABLE \\
\hline 29 & SINT 8 SEQ & 7,45 & 4,09 & 6,49 & 3,67 & 5,19 & $5,38 * *$ & ESTABLE \\
\hline 1 & SINT 1 QPM & 6,82 & 3,86 & 5,63 & 3,84 & 6,18 & 5,27 & ESTABLE \\
\hline 3 & SINT 3 QPM & 6,6 & 3,29 & 4,69 & 3,5 & 7,3 & 5,08 & ESTABLE \\
\hline 4 & SINT 4 QPM & 6,62 & 3,72 & 4,79 & 3,47 & 6,78 & 5,08 & ESTABLE \\
\hline 6 & SINT 2 Q & 7,17 & 2,69 & 4,18 & 4,06 & 7,17 & 5,05 & ESTABLE \\
\hline 17 & POB63 C2 QPM & 6,95 & 4,53 & 3,96 & 3,88 & 5,87 & 5,04 & ESTABLE \\
\hline 12 & HV-521 & 6,3 & 4,13 & 4,95 & 3,91 & 5,73 & 5,00 & $\mathrm{ADC}$ \\
\hline 21 & SINT 10 SEQ & 7,78 & 3,72 & 4,83 & 2,74 & 5,83 & 4,98 & ESTABLE \\
\hline 14 & SINT 5 SEQ & 7,13 & 5,31 & 2,66 & 3,84 & 5,5 & 4,89 & BAI \\
\hline 23 & SINT TS6 & 6,35 & 3,37 & 4,69 & 3,77 & 6,25 & 4,89 & ESTABLE \\
\hline 10 & V-556AC & 5,74 & 4,29 & 4,39 & 4,1 & 5,53 & 4,81 & ADC \\
\hline 2 & SINT 2 QPM & 6,05 & 3,59 & 4,91 & 3,49 & 5,85 & 4,78 & ESTABLE \\
\hline 13 & POB62 C6 QPM & 6,15 & 3,95 & 4,02 & 3,51 & 6,03 & 4,73 & ESTABLE \\
\hline 11 & $\mathrm{~V}-538 \mathrm{C}$ & 5,91 & 4,01 & 5,65 & 2,92 & 4,53 & 4,60 & ESTABLE \\
\hline 18 & NYANKAPALA 8763 & 5,77 & 2,21 & 5,47 & 3,6 & 5,36 & 4,48 & ESTABLE \\
\hline 19 & POB 64 C1 QPM & 5,87 & 2,97 & 4,4 & 3,42 & 5,19 & 4,37 & ESTABLE \\
\hline 24 & V-530 & 6,27 & 2,47 & 4,07 & 3,67 & 5,2 & 4,34 & ESTABLE \\
\hline 16 & POZA RICA 8763 & 6,88 & 3,45 & 3,89 & 2,88 & 4,03 & 4,23 & ESTABLE \\
\hline 15 & ACROSS 8763 & 6,54 & 2,8 & 3,57 & 3,56 & 4,63 & 4,22 & ESTABLE \\
\hline & $\begin{array}{l}\text { PROM } \\
\text { LSD }\end{array}$ & $\begin{array}{l}7,1 \\
1,51\end{array}$ & $\begin{array}{l}3,97 \\
2,0\end{array}$ & $\begin{array}{l}5,08 \\
1,8\end{array}$ & $\begin{array}{l}3,84 \\
0,00\end{array}$ & $\begin{array}{l}6,01 \\
0,00\end{array}$ & $\begin{array}{l}5,20 \\
0,84\end{array}$ & \\
\hline & $\mathrm{CV}$ & 10,1 & 17,5 & 16,8 & 15,11 & 14,7 & 14,07 & \\
\hline & FSIG & 5,0 & 5,0 & 5,0 & 0,00 & 0,00 & 1,00 & \\
\hline & REFF & 0,76 & & 0,71 & & 1,23 & & \\
\hline & $\begin{array}{l}\text { DMS0, } 05=0,64 \\
\text { DMS0,01 }=0,84\end{array}$ & & & & & & & \\
\hline
\end{tabular}

* = Significancia para tratamientos al 0,05 de probabilidad en la prueba DMS.

$* *$ = Significancia para tratamientos al 0,01 de probabilidad en la prueba DMS. 
Cuadro 5. Rendimiento medio e índices ambientales para la evaluación de variedades de maíz con alta calidad de proteína. CIRGOC 2001B.

\begin{tabular}{lcc}
\hline \multicolumn{1}{c}{ Ambiente } & $\begin{array}{c}\text { Rendimiento medio } \\
\text { t/ha }\end{array}$ & $\begin{array}{c}\text { Índice } \\
\text { ambiental }\end{array}$ \\
\hline Cotaxtla & $7,01^{* *}$ & 1,90 \\
Papantla & 6,01 & 0,80 \\
Huimanguillo & 5,08 & $-0,12$ \\
San Andrés Tuxtla & 3,97 & $-1,23$ \\
Isla & 3,85 & $-1,36$ \\
\hline
\end{tabular}

DMS $0,01=0,84$.

** = Significancia para los ambientes de evaluación al 0,01 de probabilidad

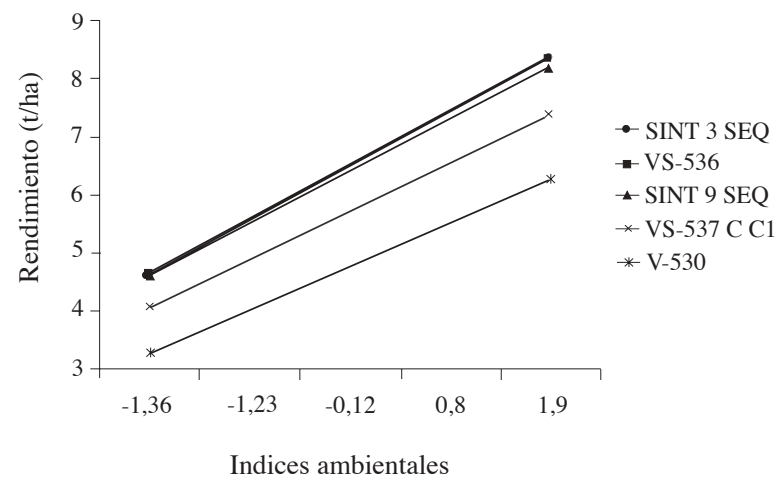

Figura 1. Tendencias de respuesta de variedades de maíz a través de ambientes. CIRGOC 2001B. de evaluación, Particularmente se observa que los genotipos SINT 3 SEQ, SINT 9 SEQ, V-537C C1 y VS-536 son genotipos "deseables" en virtud de que son sobresalientes en ambientes favorables pero también en ambientes desfavorables; Así también, V-537C C1 es una variedad con alta calidad de proteína, lo que sugiere ventajas desde el punto de vista de su adaptación, producción y la expectativa en fortalecer el nivel nutricional sobretodo en la población infantil de las áreas rurales de México.

En el Cuadro 6 se muestran las comparaciones y pruebas de t para rendimiento y los promedios de las características agronómicas más importantes para las cinco localidades de evaluación. Se observa primeramente en la comparación de genotipos normales, con alta calidad de proteína y los genotipos testigo, que los genotipos normales registraron en promedio un rendimiento de 5,57 t/ha lo que significa $14 \%$ más que los genotipos con alta calidad de proteína; Por su parte los genotipos testigo rindieron en promedio 5,26 t/ha, es decir, $7 \%$ más en relación con los maíces con alta calidad de proteína. Con relación a los genotipos sobresalientes en cada grupo, se encontró dentro de los formados con líneas tolerantes a sequía, que el SINT 3 SEQ y SINT 9 SEQ registraron rendimientos promedio a través de localidades de 6,21 y $6,10 \mathrm{t} / \mathrm{ha}$, similares al mejor testigo (VS-536), y superiores al SINT 1Q y V$537 \mathrm{C}$, en 8 y $14 \%$ respectivamente.

Cuadro 6. Comparaciones y pruebas de t para rendimiento en variedades de maíz normal y con alta calidad de proteína. CIRGOC 2001B.

\begin{tabular}{|c|c|c|c|c|c|c|c|c|c|c|c|}
\hline Núm & Comparación & $\begin{array}{c}\text { Rend } \\
\text { t/ha }\end{array}$ & $\begin{array}{r}\% \\
\text { Rel }\end{array}$ & $\mathrm{T}$ calc & $\begin{array}{c}\text { Asp } \\
\text { pl }\end{array}$ & $\begin{array}{c}\text { San } \\
\text { pl }\end{array}$ & $\begin{array}{l}\text { Asp } \\
\text { maz }\end{array}$ & $\begin{array}{l}\text { San } \\
\text { maz }\end{array}$ & $\begin{array}{l}\% \\
\text { ac }\end{array}$ & $\begin{array}{c}\% \\
\text { cob }\end{array}$ & $\begin{array}{c}\% \\
\text { pod }\end{array}$ \\
\hline \multirow[t]{3}{*}{1} & Normales & 5,57 & 114 & $8,37 * *$ & 2,72 & 2,95 & 2,54 & 2,31 & 9,37 & 5,58 & 6,24 \\
\hline & QPM & 4,9 & 100 & & 2,76 & 2,99 & 2,71 & 2,73 & 8,31 & 4,85 & 8,04 \\
\hline & Testigos & 5,26 & 107 & $2,08 *$ & 2,94 & 3,01 & 2,62 & 2,41 & 7,39 & 5,91 & 5,13 \\
\hline \multirow[t]{7}{*}{2} & SINT 3 SEQ & 6,21 & 114 & $2,29 *$ & 2,71 & 2,9 & 2,31 & 2,07 & 13,71 & 2,83 & 9,01 \\
\hline & SINT 9 SEQ & 6,10 & 112 & $1,96^{*}$ & 2,37 & 2,76 & 2,40 & 2,51 & 7,29 & 6,90 & 9,20 \\
\hline & SINT 12 SEQ & 5,74 & 105 & $0,86 \mathrm{NS}$ & 2,65 & 2,95 & 2,55 & 2,56 & 8,85 & 2,67 & 6,33 \\
\hline & SINT $1 \mathrm{Q}$ & 5,71 & 105 & $0,76 \mathrm{NS}$ & 2,5 & 2,94 & 2,25 & 2,13 & 4,76 & 5,29 & 5,82 \\
\hline & V-537C & 5,46 & 100 & & 2,88 & 3,03 & 2,50 & 2,57 & 11,7 & 6,93 & 8,83 \\
\hline & $\mathrm{V}-537 \mathrm{C} \mathrm{C} 1$ & 5,43 & 99 & $0,18 \mathrm{NS}$ & 2,72 & 2,84 & 2,50 & 2,45 & 12,87 & 2,50 & 7,59 \\
\hline & VS-536 TEST & 6,17 & 113 & $2,17 *$ & 2,56 & 2,67 & 2,25 & 2,0 & 11,75 & 1,4 & 4,21 \\
\hline
\end{tabular}

$\mathrm{T} 0,05(155)=1,96$

$\mathrm{T} 0,01(155)=2,58$

*= Significancia de la comparación al 0,05 de probabilidad

** = Significancia de la comparación al 0,01 de probabilidad

NS= No significativo 


\section{CONCLUSIONES}

Los genotipos experimentales normales con tolerancia a sequía rindieron $14 \%$ más en relación con los genotipos con alta calidad de proteína y $7 \%$ más que los genotipos testigo.

Dentro de los genotipos de maíz normal sobresalientes se encuentran los sintéticos SINT 3 SEQ, SINT 9 SEQ, SINT 12 SEQ y el testigo comercial VS-536.

De los genotipos de maíz con alta calidad de proteína fueron sobresalientes SINT 1Q, V-537C y V-537C Comp. 1

En las localidades de Cotaxtla, Papantla y San Andrés Tuxtla, Ver. V-537C Comp. 1 registró ventajas importantes en rendimiento, aspecto y sanidad de planta y de mazorca, acame, cobertura y pudrición de mazorca en relación con V-537C original.

El mejor rendimiento medio y el mejor índice ambiental se registró para la localidad de Cotaxtla y los índices ambientales más bajos fueron para San Andrés Tuxtla e Isla Ver.

\section{LITERATURA CITADA}

CARBALLO C.A.; MÁRQUEZ, S.F. 1970. Comparación de variedades de maíz del Bajío y de la mesa Central por su rendimiento y estabilidad. Agrociencia 5(1): 129-146.

EBERHART, A.; RUSSELL, W. 1966. Stability parameters for comparing varieties. Crop sci. 6: 36-40

EDMEADES, G: BÄNZIGER, M.; PANDEY, S.; BOLAÑOS, J.; CHAPMAN, S.; ORTEGA, C.A., LAFITTE, H.R.; FISCHER, K.S. 1996. Recurrent selection under managed drought stress improves grain yields in tropical maize. In: Developing drought and low $\mathrm{N}$ tolerant maize. CIMMYT, El Batán, México. p. 415-425.

EDMEADES, G:O, J. BOLAÑOS, S.C. CHAPMAN, H.R. LAFITTE AND M. BÄNZIGER. 1999. Selection improves drought tolerance in tropical maize populations: I. Gains in biomass, grain yield and harvest index. Crop sci. 39: 1306-1315.

GARCÍA, E. 1981. Modificaciones al sistema climático de Köppen. $3^{\text {a }}$ Ed. 252p.

GERÓN X.F.; RAMÍREZ, V.P.; BALDERAS M.M.; SIERRA, M.M.; ALCÁZAR, J.J. 1979. Mejoramiento genético de líneas y poblaciones con el carácter opaco duro. In: Proyectos de investigación Campo Cotaxtla. CIAGOC INIA SARH p. 47-53.
LARKINS, A.; DANNEHOFFER, J.,M.; BOSTWICK, E.O.; MORO, G.A.; LÓPEZ, M.A. 1994. What they are and how they work. In: Larkins, B.A.; Mertz, E.T. (eds.). Quality protein maize 1964-1994. Proc. of the symposium on quality protein maize. EMBRAPA/CNPMS, Sete Lagoas, MG, Brasil. p.133-148.

MÁRQUEZ, S.F. 1992. La interacción genético ambiental en genotecnia vegetal revisión. In: Sánchez G.J., Ron P.J. y Márquez S.F. Memorias del simposium interacción genotipo ambiente en genotecnia vegetal. Guadalajara Jal. p. 1-27.

MÁRQUEZ, S.F. 1988. Genotecnia vegetal. Métodos, teoría, resultados. Tomo II AGT Editor México. 665 p.

MERTZ, T; BATES, S.; NELSON, E. 1964. Mutant gene that changes the protein composition and increases the lysine content of maize endosperm. Science 145: 279-280.

MERTZ E.,T. 1994. Thirty years of opaque 2 maize. In: Larkins B.A. y Mertz E.T. (eds.). Quality protein maize 1964-1994. Proc. of the Symposium on quality protein maize. EMBRAPA/CNPMS, Sete Lagoas, MG Brasil. p. 1-10.

REYES, C.P. 1985. Fitogenotecnia básica y aplicada. AGT Editor S.A. México 460 p.

REYES, C.P. 1990. Diseño de experimentos aplicados. Ed.

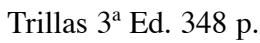

SAGAR 1998. Centro de estadística agropecuaria.

SIERRA, M.M.; RODRÍGUEZ, M.F; CASTILLO, G.R.; MÁRQUEZ, S.F. 1992. La aplicación de los parámetros de estabilidad en el mejoramiento de maíz en la región sur de México. In: Sánchez G.J., Ron P.J. y Márquez S.F. Memorias del simposium interacción genotipo ambiente en genotecnia vegetal. Guadalajara Jal. p. 239-260

SIERRA, M.M.; CANO, O.; PALAFOX, C.A.; CASTAÑÓN, G.; RODRÍGUEZ, M.F. 2000. Mejoramiento de maíz tropical para tolerancia a sequía. In: Zavala G.F., Ortega P.R., Mejía C.J.A., Benites R.I. y Guillén A.H. Memorias del XVIII Congreso Nacional de Fitogenética. Irapuato Gto. México. p. 141.

SIERRA, M.; CANO, O.; TURRENT, A.; CÓRDOVA, H.; RODRÍGUEZ, F.; SANDOVAL, A.; ESPINOSA, A.; GONZALEZ, M.; AVENDAÑO, R. 1999. Híbridos y variedades de maíz con alta calidad de proteína para el trópico mexicano. In: Memorias XVIII Reunión Latinoamericana del maíz . Sete Lagoas-Minas Gerais Brasil. p. $517-523$.

VASAL S., K. 1994. Specialty corns. In: A.R. Hallauer (ed.). CRC Press . Boca Ratón FL p. 79 